VKIT

Karlsruhe Institute of Technology

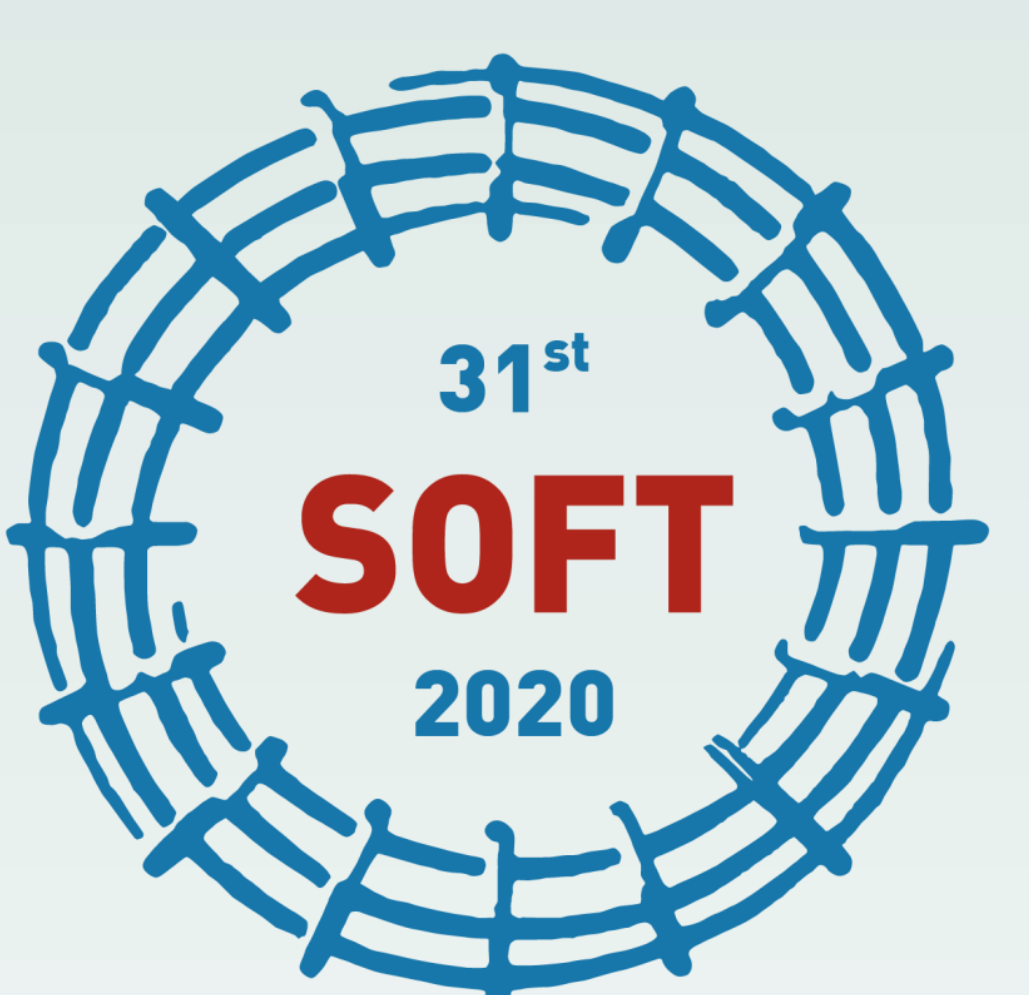

Institute for Neutron Physics and Reactor Technology (INR) Karlsruhe Institute of Technology (KIT), Campus Nord

Hermann-von-Helmholtz-Platz 1

76344 Eggenstein-Leopoldschafen, Germany

http://www.inr.kit.edu/

\title{
Heat Pipe technology based Divertor Plasma Facing Component concept for European DEMO
}

Wen Wena ${ }^{\mathrm{a}}$ Bradut-Eugen Ghidersa ${ }^{\mathrm{a}}$, Hering Wolfganga ${ }^{\mathrm{a}}$, Jörg Starflinger ${ }^{\mathrm{b}}$, Robert Stieglitz ${ }^{\mathrm{a}}$

a: Institute for Neutron Physics and Reactor Technology, Karlsruhe Institute of Technology , Karlsruhe, Germany

b: Institute of Nuclear Technology and Energy Systems, University of Stuttgart, Stuttgart, Germany

\section{Objectives}

Investigate the possibility of using water-based heat pipes in conjunction with a new divertor concept including:

- dimensioning a variable conductance heat pipe that should be capable of dealing with heat fluxes as high as (at least) $20 \mathrm{MW} / \mathrm{m}^{2}$

- analysis the integration of the HP in the divertor target

\section{Basic Concept}

- Divertor target made out of parallel cylindrical Heat Pipes installed in a water cooling channel. The HP rods form a staggered structure (HP condenser)

- The Heat Pipes penetrate the plasma facing side of the cooling channel, having a hexagon W-armor at that particular end (HP evaporator side).

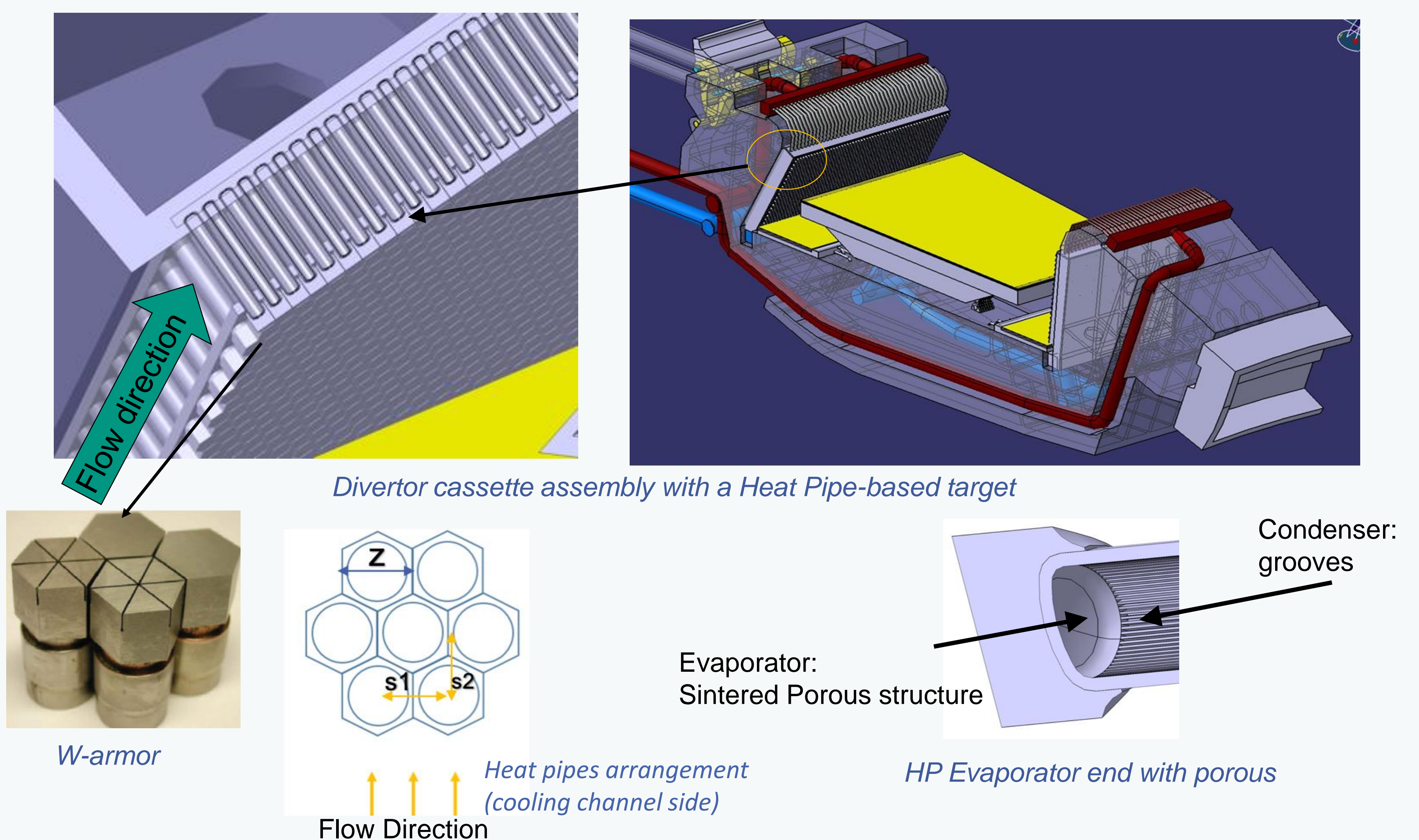

- HP has cylindrical body with outside diameter $15 \mathrm{~mm}$, while the vapor space is $12 \mathrm{~mm}$ in diameter;

- HP material: CuCrZr

- HP total length is $230 \mathrm{~mm}$, the length of the evaporator and adiabatic part being $7 \mathrm{~mm}$ and, respectively $23 \mathrm{~mm}$.

- Orientation $7.8^{\circ}$ depends on divertor target.

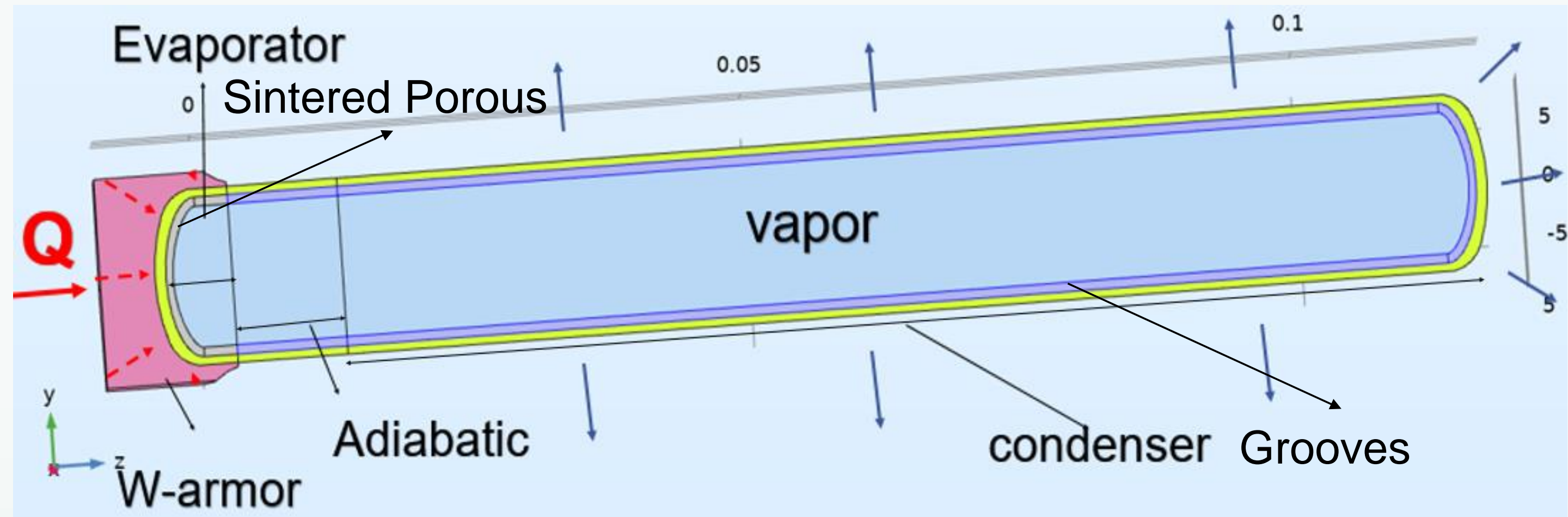

\section{Design Studies}

Power removal system: assumed to have the same mass flow rate and conditions $\left(\mathbf{4 M P a}, \mathbf{1 3 0}^{\circ} \mathrm{C}\right)$ as the EU-DEMO divertor baseline.

$\mathrm{HP}$ working medium is water: design that has a vapor temperature around $200^{\circ} \mathrm{C}$ (best performance for water-based heat pipes) and does not exceed $250^{\circ} \mathrm{C}$ (rapid fall of performance).

$>$ Find the optimal condenser length $\left(l_{c}\right)$

Four options for the capillary structure have been considered: -HP1: grooves for condenser and adiabatic zone and mesh for the evaporator HP2: grooves for condenser and adiabatic zone and sinter porous material for evaporator

-HP3: mesh for capillary structures inside

-HP4: sinter for capillary structures inside

\begin{tabular}{|l|l|l|l|l|}
\hline Design option & HP1 & HP2 & HP3 & HP4 \\
\hline Number of grooves $\mathrm{N}_{\mathrm{a}}$ & 80 & 80 & & \\
\hline Width of groove $\mathrm{w}[\mathrm{mm}]$ & 0.3 & 0.3 & & \\
\hline Height of groove $\mathrm{h}[\mathrm{mm}]$ & 1 & 1 & & \\
\hline Mesh/Wire Diameter $\mathrm{d}_{\mathrm{m}}[\mathrm{mm}]$ & 0.1 & & 0.1 & \\
\hline Mesh width $\mathrm{w}_{\mathrm{m}}[\mathrm{mm}]$ & 0.5 & & 0.5 & \\
\hline Sinter particle radius $\mathrm{r}_{\mathrm{p}}[\mathrm{mm}]$ & & 0.05 & & 0.05 \\
\hline Porosity $\varepsilon$ & 0.74 & 0.5 & 0.74 & 0.5
\end{tabular}

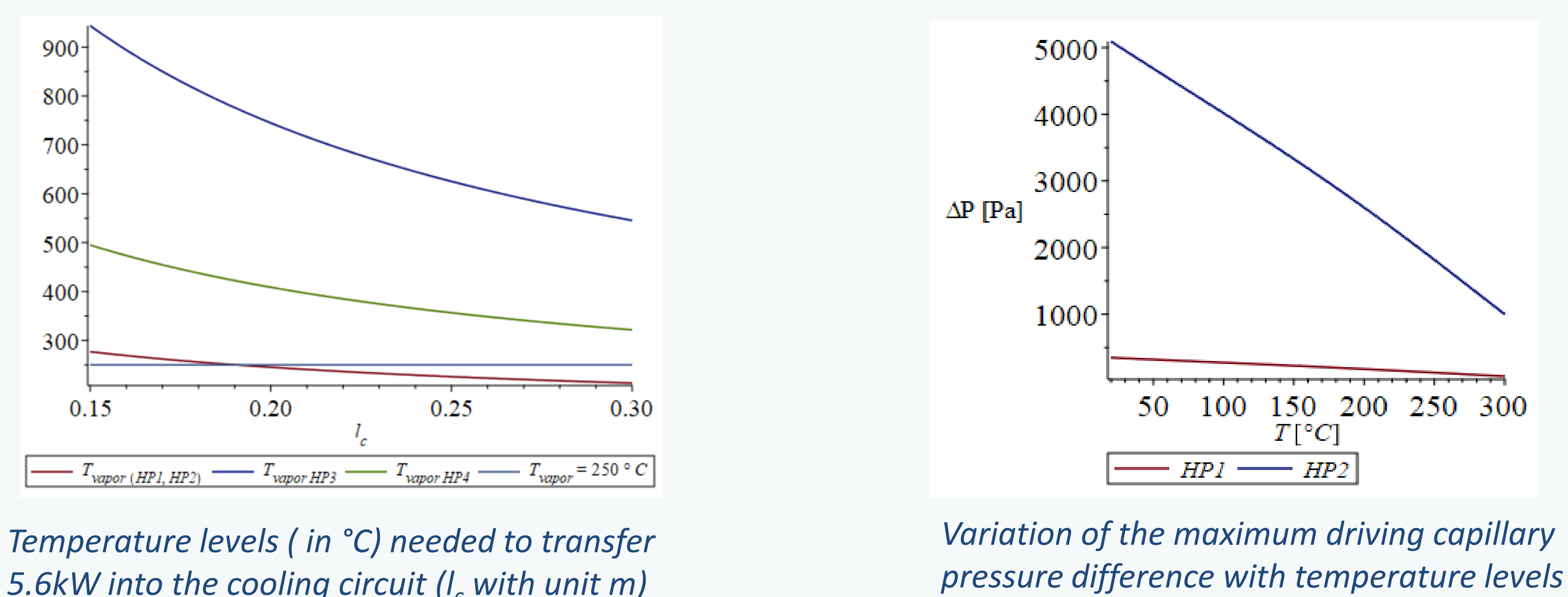

HP1 and HP2 options can operate at vapor temperatures below $250^{\circ} \mathrm{C}$ when condenser length is more than $200 \mathrm{~mm}$

- Capillary limit: HP2 has lager driving capillary pressure against pressure losses allowing for higher operational power.

- Entrainment limit: using open groove it limits the power level; adding mesh screen between groove and vapor increases that limit.

\begin{tabular}{|c|c|c|c|c|c|}
\hline \multirow[t]{2}{*}{$\begin{array}{l}l_{c} \\
{[\mathrm{~mm}]}\end{array}$} & \multirow[t]{2}{*}{$\begin{array}{l}\text { Vapor } \\
\text { Temperature [ํㅜㄹ }\end{array}$} & \multicolumn{2}{|c|}{$\begin{array}{l}\text { Capillary limit } \\
\text { [kW] }\end{array}$} & \multicolumn{2}{|c|}{$\begin{array}{l}\text { Entrainment limit } \\
\text { HP1/HP2 [kW] }\end{array}$} \\
\hline & & HP1 & HP2 & $\begin{array}{l}\text { No mesh } \\
\text { screen }\end{array}$ & $\begin{array}{l}\text { With mesh } \\
\text { screen }\end{array}$ \\
\hline 150 & 277 & 1.6 & 5.57 & 5.7 & 16 \\
\hline 200 & 245 & 2.2 & 7.5 & 5.7 & 16 \\
\hline 220 & 234 & 2.5 & 7.9 & 5.6 & 15.6 \\
\hline 250 & 226 & 2.6 & 8.3 & 5.4 & 15.2 \\
\hline 300 & 212 & 2.8 & 8.5 & 5.1 & 14.5 \\
\hline
\end{tabular}

\section{Conclusions}

- Solution: A water based heat pipe $230 \mathrm{~mm}$ long made out of $\mathrm{CuCrZr}$, from which the condenser should be at least $200 \mathrm{~mm}$ long, should be capable for peak heat flux of $20 \mathrm{MW} / \mathrm{m}^{2}$

\section{Futures works}

- The operating limits here using engineer formulas need to be validated experimentally.

- The first experiment focus on evaporator is under preparation. 